\title{
An Analysis Of The Position Of Assistant Principal Of The Year In Indiana: An Analysis Of What Is Really Important
}

\author{
Dr. Stephen D. Mercer, University of Phoenix, USA
}

\begin{abstract}
This work is an analysis of the alignment between schools associated with an Indiana Assistant Principal of the Year, as selected by the Indiana Association of School Principals, and increases in academic performance of those schools on state mandated "high stakes" academic tests. The focus was on school improvement using annual school report card data. Using a design looking for association and a Chi Square analysis, a significant positive correlation was identified. The results shed some light on the potential excellent practices of assistant-principals and student academic achievement gains. Although a positive correlation was found, the results can only give ideas for leadership consideration. They are not considered predictive because of the ex-post facto nature of the data allowing for no manipulation of variables.
\end{abstract}

Keywords: Assistant Principal; Indiana Principal of the Year; Indiana Association of School Principals

\section{INTRODUCTION}

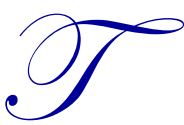

his analysis was conceived in a somewhat unique manner. The researcher was an active school administrator for 32 years. In 2007 he retired from the position of school superintendent and pursued dreams that seemed unattainable while fully engaged in leading a school district. His adventures have been varied and interesting. Most important, these adventures have kept his desire to explore the details of what makes life great alive and well. Understanding the role of excellence and creativity in the world has become a mission for him. He believes that understanding the simple things in life is the gateway to a richer understanding of the complex constructs that seem necessary in our society.

As a professor for the University of Phoenix, School of Advanced Studies and their College of Education, he has kept his desire for seeing excellence in education alive. He has been doing that for nine years. This has kept his online facilitation skills and his dreams to make a difference in public education alive. A series of interesting paths led him to a position in life where he was looking for a new adventure with a schedule that aligned with his wife's k12 school schedule. That path led him to taking on the somewhat unlikely position of substitute school bus driver for a large, but rural, school district in Northeast Indiana. He liked children, he had a passion for seeing public education done well, and had never held this particular position in a school.

Being the only Ph.D. bus driver the school district ever had was something to be kept "under wraps." That was because the position brought on new challenges and a myriad of "new driver" mistakes. Having been the Chief Executive Officer for a somewhat complex school district had little correlation with the ability to perform the complex, yet somewhat rudimentary, duties expected of a school bus driver. Yet, there was a real sense of satisfaction that came with interacting with children on the bus. There was also an increasing interest in watching officials at the local school he serviced. He was no longer a participant in the day-to-day activities of running a school. However, there was an interest, a curiosity, and an appreciation for what happened in the view he had from the windshield of a 72 passenger "cheese wagon." 
One morning, while observing and appreciating what was going on in front of his eyes, he spotted the school's assistant principal working with school bus drivers, teachers, and students in a very confident, self assured, and professional manner. That view was inspirational and reassuring for a person who had dedicated his life to what he considered the most important profession in the world. He felt a little pride as he realized that there was a time his professional satisfaction came from doing really important, front line, and take charge activities for a school.

Immediately, however, that view and the associated self aggrandizement ended when he heard over the radio in the bus a very loud and directive female voice say "Woo-- Bus 2-- STOP." The "self confident" Ph.D. and former superintendent was driving Bus \#2. He immediately stopped his bus and was met at his driver side window by the assistant principal. It was not a "good morning, how are you meeting." She was upset with him. Her body language screamed that sentiment. She began to describe, in an emotionally charged way, how important it was stay parked until she released buses to leave the parking area. As it was, students were still boarding the bus that was next in line and movement in the parking lot was just not appropriate. A child could be harmed.

She was right and he was embarrassed. This embarrassment led to self reflection that further led to some well deserved humility. This bus driving adventure was really fun; however, he did bow his head and pray that he not be responsible for harming a child each day as he left the bus lot. The thought that his worst nightmare could have happened was at the forefront of this attention. He remembered this was an adventure, not a job. In reality, each morning he rose at 4:00 a.m. and went through a variety of activities culminating at his first stop, then continued 35 or so miles through an overtly twisted route to the school for-- $\$ 30$ before taxes. It was time for the self appointed anthropologist to return to reality. There was a structure that needed to be followed ardently. There was more than just having fun watching and working with kids. There was an important overriding set of factors and rules that needed to be followed. This structure and these rules, at this time and in this place, were fully entrusted to an energetic, spirited, very young, professional lady.

The driver was on a "long term" substitute assignment so he had to opportunity to observe the energy, confidence, and professionalism of this Assistant Principal on a daily basis. She smiled a lot, she interacted with children, she was friendly, yet she was confident and had a special kind of professional sense about her that seemed to transcend rules in a very commanding way. Daily observation forced the "old administrator/new bus driver" to wonder. He wondered if he had the skills to do what she was doing somewhat intuitively. Then he wondered where she got her direction, her energy, and her ability to confidently "step up" and lead. He wondered what gave that young lady the sense that she was a role model, an exemplar, and a guide. Where did she get her inter-strength and her sense for what was really important instantly? She seemed to be able to make decisions and act instantly.

One day he realized that this young assistant principal was selected as assistant principal of the year for her region of Indiana. This was huge since she was selected from a geographic area including 10 counties. He scheduled a meeting with her. He was "up front" describing his adventure. Then they discussed her passions for education, her sources of renewal, where she got her guidance, and where she gets her real sense of right and wrong. She glowed as she talked about her career. She spoke of her peers in other schools and of her husband as sources of inspiration.

The meeting was held in her office. Both she and the researcher were somewhat overcome by nasal congestion and the beginnings of colds. However, there was a quick bond that seemed to center around their mutual love for the profession of educational leadership. She was proud of being selected as assistant principal of the year for her region and freely shared the criteria that were used for her selection. She had not directly aspired to the position, but she was certainly proud of the designation. She shared a lot of the things that made her proud of the contribution she was making to her school, its community, students, families, and her profession. She was appropriately humble, but not the least bit shy about her convictions.

The researcher is not driving that bus any more. However, he gained some insights that made a difference in his life. It validated his professional endeavors and confirmed his faith in a profession that is going to continue to change the world for the better. Meeting that assistant principal made a difference in his understanding of some of the great things happening in public education today. 


\section{Assistant Principals}

Assistant principals are individuals that are close to the heart of instruction in most schools and affect a lot of change and assert a lot of grass roots leadership. One might think this is because of great administrative planning, great collegiate preparation, and good leadership. However, their successes often result from attempts to reconcile what they learn from constant interaction with students, teacher, parents, and various school employees. Assistant principals must interact with students, teachers, cooks, custodians, bus drivers, parents, and community members while their superiors are in offices completing reports, in board rooms discussing leadership issues, legal dilemmas, and other things. Almost by default, assistant principals are the individuals that provide the only front line interaction many stakeholders have with the administration of a school. They become the "de-facto face of a school and its administration." When asked direct questions, they do not have the luxury of going to the board room to discuss possible responses among a well educated and properly skilled administrative team. They need to react positively and in a manner that serves the best interest of the school and the essence of why it exists. (Oliver, 2005)

For many assistant principals, this is their first administrative position. Others have moved into their positions from administrative positions in smaller school districts or smaller school buildings. Their involvement in classrooms as teachers is often more recent that most others on an administrative team. They are often trusted as understanding the needs of classroom teachers and the day to day function of schools yet recognized as new to the role of school administrator. They feel this too. Their significant professional experiences have been in the classroom and their graduate training has not specifically focused on, and perhaps not even addressed at all, their current role. Further, they generally do not have peers within their building to collaborate with. They can benefit from recent, first-hand knowledge of what teachers and students need from administrators to do their jobs well. They are also familiar with the pressures teachers feel as they work to balance the needs of students with the administrative pressures for students to meet the ever evolving performance measures identified by state departments of education. Yet, when hard decisions are to be made they can feel isolated. (Grodzki, 2011)

\section{Focus of Leadership}

Traditional leadership programs for school administrators focus on the positions of principal or superintendent. There is a dearth of collegiate programming focused on developing great assistant principals. Because of this void, individuals assuming the position of assistant principal do so with little formal training specifically focused on their position. Some would even see the position as a "stepping stone" to administrative positions of greater stature. (Herrington \& Kearney, 2012)

Assistant principals are expected to meet the needs of their subordinates, superiors, and various stakeholder groups on a regular basis. The myriad of pressures coming at them are not prioritized. They cannot be considered in isolation. They must all be addressed in one way or another. Getting the prioritization and the mix right can lead to great success or disaster. Too much focus on any one area or too little focus on another can lead to derailment of an otherwise "budding" administrative career. They are formally evaluated by administrative superiors but they are informally evaluated daily by those they serve. Although part of an administrative team, assistant principals are often seen as individuals challenged with proving their ability to meet under-defined and often allusive performance measures. (Marshall, 1991)

Great assistant principals need to make moral and ethical decisions in ways that make a real difference in lives. Their training to be teachers and their experiences in the classroom has brought them to that understanding. Their decisions need to be made quickly and must be customized to meet the needs of "real world," contextual settings where participants do not care much about "the big picture." Thus, an assistant principal's decisions and directives must come from an internalized philosophy that resonates with their beings. The way messages are delivered is often as important, or even more important, than the message itself. Mistakes will be made. When they are, there is an expectation that they will be corrected with direct diligence in a confident and energetic manner. All of this needs to be done with little or no formal training for the position the assistant principal is currently occupying. (Rintoul \& Goulais, 2010) 
This need for authoritarian decisiveness, uniquely embodied in an unquestionable sense that enforcing rules, is a somewhat miniscule subset of a greater mission to guide human development. For assistant principals, modeling exemplary behavior is very important. This goes beyond the regularly identified work hours. As a strong willed individual, an assistant principal can be occasionally in error but never in doubt. For those of us fortunate enough to call one "friend", our lives continue to be enriched by his or her presence and common sense messages on how to better ourselves. (Grodzki, 2011)

Yet, one is forced to question where assistant principals get their guidance and strength. Any administrator that has worked during the past three or four decades knows that there have been intense pressures on administrators and schools to work, in whatever ways are possible, to raise student achievement on standardized tests and other identified performance measures. Failure to maintain this focus at all levels has been seen as poor school leadership. School districts and school building have received grades from state departments of education based exclusively on student performance. These grades often mirror the grades given to students. Good performing schools are assigned the grade of $\mathrm{A}$ while poor performing schools are given the grade of $\mathrm{F}$ and thus designated as failing. (Munzo \& Barber, 2011)

\section{The Call for Student Achievement}

All school administrators in contemporary schools feel pressure to increase or maintain student performance as measured by a variety of factors including scores on standardized tests, student attendance rates, promotion rates, and graduation rates. There are some jurisdictional differences, but the expectation that schools will meet or exceed established standards is ubiquitous. Assistant principals can do what they believe is right and be generally meeting the needs and desires of superiors, subordinates, and stakeholders and still be part of a schools that are identified as failing. This can create real professional dilemmas for assistant principals. If they fail to meet the needs of stakeholders they have failed in their eyes. If school performance is not exemplary or improving their efforts are also recognized as failing. Yet, there seem to me no models, no sets of best practices, no collegiate training programs, and no administrative theories that show assistant principals how to do their jobs effectively. (Munzo \& Barber, 2011)

Benchmark performance measures for assistant principals can be somewhat allusive. Their professional behavior must be guided by a set of internal standards that are stable and that radiate from an internal understanding of the factors that are really important. This goes far beyond the external pressures they feel. It also goes far beyond any specific guidance given to them by administrative policies, job descriptions, or formal evaluation processes. (Grodzki, 2011)

While assistant principals can find it difficult to resolve the dilemma caused by trying to follow rules externally imposed on them while doing what they believe is best for the children they serve. Meeting the pressing requirements for accountability and at least managerial compliance with regulatory requirements, increasing daily demands for reaction to emergent issues, and senior administration's expectations for continual instructional leadership can result in feelings of inadequacy and self-doubt. (Grodzki, 2011)

Assistant principals seek guidance and support from their colleagues. This can come in a variety of ways. As a practical reality, an assistant principal often has no peer within his or her school. They seek guidance from superiors; feel pressures from stakeholders; and pull from their internal professional, internalized values as they strive for excellence. Although this is all important and appropriate the biased nature of these sources of guidance can cause stress in an assistant principals working hard to excel in both their current position and their profession. (Oleszewski, Shoho \& Barnett, 2012)

Strong involvement with professional organizations that deal with the position of assistant principal can he helpful. Collegial relationships can allow for assistant principals to "vent" frustrations and a venue to brainstorm ideas in a non-threatening way. It also provides a focused way to bring specialized professional development opportunities to a position that has been neglected by the traditional k-12 administrative training venues.

Indiana Assistant Principal of the Year Program 
The Indiana School Principals Association (IASP) gives great support for the position of assistant principal. The organization has a division specifically focused on the position of assistant principal. They recognize the critical nature of this position as it relates to the improvement of schools. Their view of the position goes beyond the contemporary measures of school improvement that have swept our nation. They strive to focus on what is good for schools and the communities they serve. They also work to develop regional and statewide structures that facilitate peer interactions among assistant principals. (Indiana Association of Principals, 2012.

In the state of Indiana, assistant principals have the opportunity to be recognized for exemplary performance on an annual basis. This program is operated by the IASP. Annually, an outstanding assistant principal of the year is selected for each identified region of the state. From that selection an assistant principal of the year is selected. The criteria for assistant principal of the year center on the some pretty traditional standards for good school leadership. They include: (1) active involvement professional organizations, (2) personal involvement with their local community, (3) linking the local community with their schools (4) working with teacher to implement or support programs that foster student learning, (4) taking risks to improve school, and (5) taking an active role in improving school climate for students and staff. (Indiana School Principals Association, 2012)

\section{Student Performance in Principal of the Year Buildings}

The Indiana Department of education rates schools based on a completely different criteria. They rate schools annually and identify each Indiana School building as performing at the A, B, C, D, or F level. This annual designation is the result of statistical analysis of student performance on standardized tests and closely aligned subjective measures like student attendance, student promotion rates, and graduation rates. (Indiana Department of Education, 2012)

The difference between the focus of the Indiana Association of Principals criteria for assistant principal success and the criteria the Indiana Department of Education uses to evaluate school building seem to be misaligned. The professional organization focuses on administrative activities and practices and does not formally consider the final results of these actions as they may or may not relate to student achievement measures. The department of education focuses only on results and does not seem to care much how they are achieved. It could be concluded that the Indiana School Principals organization is focused on recognizing excellence in administrators based on one set of criteria while overall school success will be measured on a quite different set of standards. An analysis of data suggests that there may be a professional alignment that is not immediately recognized and has here-to for not been explored.

An analysis of 1,757 public, non-charter school buildings in Indiana was conducted. Their performance, as identified by the Indiana Department of Education for the 2012, 2011, and 2010; was explored. Overall, It was found that $309(27.59 \%)$ buildings were rated A all three years, $704(40.01 \%)$ showed improvement in 2012 over either 2011 or 2012; while the remaining 744 (42.34\%) buildings showed static or decreased performance during 2012 when considered against their performance for 2011 and 2010.

Further analysis considered school buildings in Indiana that had at least one regional assistant principal of the year in either 2012, 2011, or 2010. This analysis considered 49 buildings. Of these buildings was found that $4(8.16 \%)$ buildings were rated A all three years, 32 (65.3\%) showed improvement in 2012 over either 2011 or 2012, while the remaining $13(26.53 \%)$ buildings showed static or decreased performance during 2012 when considered against their performance for 2011 and 2010 .

To determine the significance of the difference among groups a Pearson Chi Square analysis of association was applied to the data. This was done to determine if there was a significant difference between the performance of schools with a regional assistant principal of the year for 2012, 2011, or 2010 when compared with the performance of the general population of public, non-charter schools for the same years. School performance was identified as (1) Indiana public, non-charter school buildings attaining an A grade as identified by the Indiana Department of Education for 2012, 2011, and 2012; (b) Indiana public, non-charter school buildings attaining a grade from the Indiana Department of Education during 2012 that was higher than the score attained by that building for 2011 or 
2012; and (3) Indiana public, non-charter school buildings attaining a grade from the Indiana Department of Education during 2012 that was lower than a score attained by that building for 2011 or 2012.

Overall, 1,757 school buildings' ratings were considered. Of them, 309 (17.6\%) were given the grade of A for 2012, 2011, and 2010; 704 (40.1\%) showed improvement in 2012 over either their score in 2011, 2011, or both 2011 and 2012; and 744 (42.3\%) did not have an improved score for 2012 when considered against the score they achieved for 2011 or 2010. A directed sample of the population that consisted of school buildings that had an identified regional assistant principal of the year for 2012, 2011, and/or 2011 was reviewed. In this sample $4(8.2 \%)$ were given the grade of A for 2012, 2011, and 2010; 32 (65.3\%) showed improvement in 2012 over either their score in 2011, 2011, or both 2011 and 2012; and 13 (26.5\%) did not have an improved score for 2012 when considered against the score they achieved for 2011 or 2010.

\begin{tabular}{l|c|c|c}
\multicolumn{1}{c}{ All A's } & Improved & Not Improved \\
\hline Overall & $309(17.6 \%)$ & $704(40.1 \%)$ & $744(42.3 \%)$ \\
\hline With Outstanding A.P. of Year & $4(8.2 \%)$ & $32(65.3 \%)$ & $13(26.5 \%)$ \\
\hline
\end{tabular}

An analysis was done to determine if the difference between the achievement results of Indiana school buildings in general was significantly different from the sample of Indiana school buildings with a designated assistant principal of the year. To do this the Pearson Chi Square test for association was used. Expected school performance of schools in the sample was calculated based on the population considered. It was calculated that schools in the sample were expected to have 9 (17.6\%) given the grade of A for 2012, 2011, and 2010; 20 (40.1\%) showing improvement in 2012 over either their score in 2011, 2011, or both 2011 and 2012; and $21(42.3 \%)$ not have an improved score for 2012 when considered against the score they achieved for 2011 or 2010.

\begin{tabular}{|c|c|c|}
\hline & Expected & Observed \\
\hline All A’s & $9(17.6 \%)$ & $4(8.2 \%)$ \\
\hline Improved & $20(40.1 \%)$ & $32(65.3 \%)$ \\
\hline Not Improved & $21(42.3 \%)$ & $13(26.5 \%$ \\
\hline
\end{tabular}

The Pearson Chi Square Analysis for association showed the difference between performance of students from school buildings with an assistant principal of the year as recognized by the Indiana Association of School Principals for 2012, 2011, and/or 2012 was significantly different from the general population of school districts considered for the same period. The significance was below the $\mathrm{p}<.01$.

\section{CONCLUSION}

This significance does not suggest a correlation because the nature of the analysis was ex post facto. It was not a scientific analysis because no variable were manipulated. Further, a myriad of variables were not considered or controlled for. However, the analysis does allow for the identification of a relationship.

Interpretation of results will vary from district to district. However, there is evidence to suggest that there is a relationship between school buildings that perform well or improving in Indiana and buildings with regional assistant principals of the year, as designated by the Indiana Association of School Principals, is significant. Prudent school leaders pressured with the mandates to improve student performance may be well advised to consider a multi-faceted approach guiding, supporting, and evaluating assistant principals that work with students, teachers, parents, and other stakeholder groups on a regular basis.

Remembering the significant factor used for selection of assistant principal of the year by the Indiana Association of School Principals should be explored as factors to be used in guiding assistant principals. They center on supporting community involvement, encouraging innovation and risk taking, and supporting teachers. Some of us remember those factors being important long before accountability measures took the forefront. 
Performance measures and objective testing are criterion based assessments that can give important insights into school performance. Yet, the essence of what makes a school a strong community asset cannot be evaluated on such strict, objective measures. There continues to be a strong case for supporting teachers and strong linkages with communities. There is a lot to be said for encouraging creativity and innovation in a profession that is kept dynamic constant interaction with the lives of human beings. Likewise, opportunities for collegial activity among assistant principals seems important to their wellbeing and their growth as professionals.

Future studies should consider ways that characteristics that have made assistant principals reach exemplary levels can be explored and fostered. There is a bit of a suggestion in this research that much of the success assistant principals realize is gained through non-traditional sources. Even though there is a lack of formal training for this position, there is a wealth of knowledge and expertise that is being used by tremendous professionals that represent all school administrators very well.

\section{AUTHOR BIOGRAPHY}

Dr. Stephen D. Mercer has served in administrative roles in public k-12 schools for more than three decades. During his tenure in public education he has focused his leadership on school improvement seeking to best serve the needs of children, families and communities. All of his collegiate training has been in the field of education with all of his graduate work in the area of school leadership. Dr. Mercer has been associated with the University of Phoenix School of Advanced Studies for more than a decade. In this role he serves as classroom instructor and doctoral advisor. Email: Lion197067@email.phoenix.edu

\section{REFERENCES}

Grodzki, J. S. (2011, December). Role identity: At the intersection of organizational socialization and individual sensemaking of new principals and vice-principals. Canadian Journal of Educational Administration and Policy, (127).

Herrington, D. E., \& Kearney, W. S. (2012). Assistant principal career transition (Part I). National Forum of Educational Administration \& Supervision Journal, 29 (2), 80-94.

Indiana association of school principals. (2012). Retrieved from http://www.iasp.org/

Indiana department of education. (2012). Retrieved from http://www.doe.in.gov/

Marshall, C. (1991). The assistant principal: Leadership choices and challenges. Thousand Oaks, CA: Corwin Press.

Muñozo, M., \& Barber, H. (2011, May). Assistant principals in high-stakes accountability environments: The effects of job attributes and school characteristics. Educational Assessment, Evaluation \& Accountability, 23(2), 131-142.

Oleszewski, A., Shoho, A., \& Barnett, B. (2012). The development of assistant principals: A literature review. Journal of Educational Administration, 50(3), 264-286.

Oliver, R. (2005, Fall). Assistant principal professional growth and development: A matter that cannot be left to chance. Educational Leadership \& Administration: Teaching \& Program Development, 17, 89-100.

Rintoul, H. M., \& Goulais, L. (2010, November). Vice principalship and moral literacy: Developing a moral compass . Vice Principalship and Moral Literacy: Developing a Moral Compass , 38(6), 745-757. 
NOTES 